\title{
Gênero e formação em Psicologia: sentidos atribuídos por estudantes à saúde do homem
}

\author{
Gender and Training of psychologists: meanings attributed by students to men's health \\ Género y formación en Psicología: sentidos atribuidos por estudiantes acerca de la salud de \\ los hombres
}

\author{
Alberto Mesaque Martins* \\ Flávia Lemos Abade \\ Maria Lúcia Miranda Afonso***
}

\begin{abstract}
Resumo
Apresenta-se uma pesquisa qualitativa desenvolvida por meio de um grupo focal com graduandos em Psicologia, visando a conhecer os sentidos que eles atribuem à relação entre gênero e saúde, em especial à saúde do homem. A pesquisa se apoiou nas teorias de gênero e nos estudos sobre a formação em Psicologia, em interlocução com o campo da saúde coletiva. Os resultados revelam que os sentidos enunciados pelos sujeitos se encontram marcados pelos modos de produção da existência, especialmente por suas experiências no trabalho e na família, refletindo na maneira como eles percebem a vinculação dos homens às ações e práticas de saúde. Defende-se a incorporação da temática de gênero e saúde na formação em Psicologia, em uma perspectiva crítica e propositiva, e não meramente cognitiva, levandose em consideração os princípios do Sistema Único de Saúde.
\end{abstract}

Palavras-chave: Gênero. Formação do psicólogo. Psicologia social. Educação. Saúde pública.

\footnotetext{
Abstract

The paper presents a qualitative research with a focal group composed of Psychology students. It analyzes the meanings the students attribute to the relationship between gender and health, especially to Men's Health. The research was based on gender theories and on studies about education in

Texto recebido em fevereiro de 2013 e aprovado para publicação em agosto de 2014.

- Doutorando e mestre em Psicologia pela Universidade Federal de Minas Gerais (UFMG), psicólogo graduado no Centro Universitário UNA, professor nos cursos de Psicologia e CST em Recursos Humanos da Faculdade Pitágoras e na PósGraduação em Intervenção Psicossocial no contexto das Políticas Públicas (Centro Universitário UNA). Endereço: Rua Célio de Castro, 474, bloco 3, ap. 303 - Floresta, Belo Horizonte-MG, Brasil. CEP: 31110-000. E-mail: albertomesaque@yahoo. com.br

* Doutoranda em Psicologia pela PUC Minas, mestra em Psicologia, coordenadora do Curso de Psicologia do Centro Universitário UNA de Belo Horizonte, psicóloga. Endereço: Rua Walter Guimarães Figueiredo, 55, ap. 601 - Buritis, Belo Horizonte-MG, Brasil. CEP: 30492-030. E-mail: flavia.abade@prof.una.br

** Doutora e mestra em Educação, psicóloga social e clínica, professora no Mestrado em Gestão Social, Educação e Desenvolvimento Local (Centro Universitário UNA-BH). Endereço: Avenida Prudente de Morais, 135, sala 310 - Cidade Jardim, Belo HorizonteMG, Brasil. CEP: 30350-093. E-mail: luciaafonso@ibest.com.br
} 
Psychology, considering their interrelation with Collective Health. The meanings expressed by the students are marked by their modes of life production, especially by their experiences in work and family, influencing their perceptions about men and health care. The paper defends the incorporation of the discussion about gender and health in the course of Psychology, within a critical and propositional perspective, not only cognitive, considering the guidelines of the Unified System of Health (Sistema Único de Saúde).

Keywords: Gender. Psychologist education. Social Psychology. Education. Public health.

\section{Resumen}

El artículo presenta una investigación cualitativa con un grupo focal compuesto por estudiantes de Psicología, teniendo por objetivo conocer los sentidos que ellos atribuyen a la relación entre género y salud, especialmente la salud del hombre. La investigación fue basada en las teorías de género y en los estudios acerca de la formación en Psicología, en interlocución con la Salud Colectiva. Los resultados revelan que los sentidos enunciados por los individuos se encuentran marcados por los modos de producción de la existencia, sobre todo por sus experiencias en el trabajo y en la familia, repercutiendo en la manera como ellos perciben la vinculación de los hombres con las acciones y prácticas de salud. Se defiende la incorporación de la temática de género y salud a la formación en Psicología, desde una perspectiva crítica y propositiva, no sólo cognitiva, de acuerdo con los principios del Sistema Único de Salud.

Palabras clave: Género. Formación en Psicología. Psicología social. Educación. Salud pública.

\section{Introdução}

A saúde do homem é uma temática que vem ganhando importância nas últimas décadas do século XX, no campo da saúde coletiva (Gomes, 2008). No Brasil, as preocupações com o processo de saúde/adoecimento da população masculina se encontram traduzidas na recente institucionalização da Política Nacional de Atenção Integral à Saúde do Homem (PNAISH), criada em 2009, que tem como principal objetivo promover a melhoria das condições de saúde da população masculina, especialmente a redução da morbimortalidade dos homens, por meio de ações que favoreçam o seu acesso aos serviços públicos de saúde (Brasil, 2009).

A inserção da população masculina na pauta de discussões em saúde deveu-se sobretudo aos novos sentidos atribuídos ao conceito de gênero, ressignificado 
pelos movimentos sociais, que passaram a incorporar novos referencias teóricos que buscavam o rompimento com a perspectiva binária, compreendendo gênero como uma categoria histórica, analítica e relacional. Entretanto, a incorporação dessa perspectiva na formação profissional na área da saúde coletiva não parece ter acompanhado o avanço da política. Neste artigo, discute-se sobre a inserção do conceito de gênero na graduação em Psicologia, refletindo sobre a preparação dos futuros psicólogos para atuar na área da saúde e da saúde do homem.

Como aponta Ferreira Neto (2010), o Sistema Único de Saúde (SUS) constitui-se hoje em importante cenário para atuação de psicólogos. Assim, é válido indagar como o tema da saúde coletiva vem sendo incorporado à formação em Psicologia, bem como a perspectiva de gênero nessa interlocução.

\section{A Psicologia e a formação em saúde coletiva}

No Brasil, a Psicologia foi reconhecida como profissão e regulamentada pela Lei 4.119, de 27 de agosto de 1962. Nesse mesmo ano, o Conselho Federal de Educação (CFE) instituiu o currículo mínimo para os cursos de Psicologia. Entretanto foi apenas a partir da institucionalização das políticas públicas de caráter universal, com base na Constituição Federal de 1988, que uma nova realidade político-institucional se colocou para o trabalho dos psicólogos, chamados a atuar em novos contextos, como a saúde pública, a saúde mental e outros (Ferreira Neto, 2011).

Em 1990, foi criado o Sistema Único de Saúde (SUS), ancorado em uma nova concepção da saúde, associada à qualidade de vida e para além da mera ausência de doenças, no qual a participação popular nos processos decisórios é fundamental. Surgia a demanda por profissionais capazes de atuar sobre os determinantes sociais da saúde, como a pobreza, o saneamento básico, a habitação, entre outros. Trabalhadores formados em campos diversos passam a ser requisitados para atuar no âmbito da saúde coletiva. Para os psicólogos, a grande porta de entrada no SUS foi o movimento de Reforma Psiquiátrica, que rompia com a perspectiva asilar e manicomial, trazendo a necessidade de rever conhecimentos e práticas em Psicologia (Ferreira Neto, 2010).

Segundo Ferreira Neto (2011), nesse contexto, os psicólogos se viram às voltas com novos desafios:

a) uma clientela com demandas distintas daquelas colocadas pelos pacientes nos consultórios;

b) a atuação dentro das novas condições de trabalho ligadas ao sistema de saúde; e 
c) a necessidade de diálogo e interlocução com outras profissões e saberes, visando a organizar o trabalho em rede como ação coletiva e contextualizada.

Nesse cenário, como situar a Psicologia como Ciência e Profissão? Em 2004, foram elaboradas novas Diretrizes Curriculares para o Curso de Psicologia, recomendando a implicação dos psicólogos nas transformaçōes sociais e definindo não apenas os saberes, mas também as competências e habilidades necessárias para a atuação profissional (Guareschi, Dhein, Machry \& Bennermann, 2010).

Entretanto, estudos apontam o distanciamento da formação em Psicologia das políticas públicas de saúde (Ferreira Neto, 2011). Além disso, como observa Romagnoli (2011), a articulação da Psicologia com o SUS é mais complexa, tendo em vista que não se trata de uma profissão exclusiva da saúde, mas está no campo das Ciências Humanas e Sociais, com atuação em diferentes áreas, como a educação, organizações, movimentos sociais, clínica, entre outras.

Trabalhando no SUS, o psicólogo deve buscar, nos diferentes pontos da rede, a perspectiva da integralidade (Ferreira Neto, 2010), o que requer uma dimensão dialógica, pautada na escuta atenta dos profissionais às necessidades de saúde das pessoas (Mattos, 2004). Isso implica compreender as especificidades, as potencialidades e as vulnerabilidades da população em seu contexto de existência e ter os direitos humanos como perspectiva transversal à prática. Nesse contexto, insere-se a importância de se desenvolver uma perspectiva de gênero, por meio de políticas públicas que consideram as especificidades de homens e mulheres, tais como a Política de Atenção Integral à Saúde da Mulher (PAISM) e a Política Nacional de Atenção Integral à Saúde do Homem (PNAISH).

\section{A perspectiva de gênero e a integralidade do cuidado em saúde}

Em diversos campos do conhecimento (inclusive na Psicologia), considerou-se, até meados do século XX, que mulheres e homens eram diferentes por natureza, desconsiderando-se o processo de socialização e as implicações do contexto sociocultural na construção da identidade, dos pensamentos, sentimentos e desejos (Louro, 2001). Nessa perspectiva, as mulheres seriam dotadas de um instinto inato que as predispunham à maternidade e ao cuidado da prole, enquanto os homens estariam fadados aos impulsos agressivos, à violência e à inconstância sexual (Gonçalves, 1998). Todavia também foram relevantes as resistências intelectuais e políticas contra essa dominação simbólica.

Germinadas no século XIX, as lutas feministas adentraram o século XX fincando bandeiras e contribuindo para analisar os mecanismos de opressão na 
sociedade (Louro, 2001; Vazques, 2011). Izquierdo (1998) propõe compreender essa história com base na concepção de ondas feministas. A primeira onda resistia à dominação masculina e abrangia a reivindicação ao direito ao voto, ao trabalho e aos estudos. A segunda onda surgiu na década de 1960, quando os temas como organização familiar, direitos sexuais e reprodutivos passaram a ser incorporados pelas feministas (Gonçalves, 1998). Emprestado do campo da gramática, o conceito de gênero foi ressignificado na efervescência do movimento feminista. Gênero passou a ser utilizado para antagonizar o conceito de sexo, de modo que este se referia à estrutura biológica e anatômica do indivíduo (pênis/vagina), enquanto gênero estaria relacionado ao processo de construção histórica de papéis sociais com base nas diferenças sexuais entre homens e mulheres (Louro, 2001).

A segunda onda do feminismo deu origem a uma série de "estudos sobre mulheres" que vieram desbravar um território, mas, ao mesmo tempo, carregaram para dentro dele alguns mapas já instituídos (Gonçalves, 1998; Vazques, 2011). Ou seja, naquele momento, o conceito de gênero ainda carregava uma estrutura binária, mantendo polos distintos e contraditórios, em que, de um lado, estariam os homens e, do outro, as mulheres (Izquierdo, 1998). Nessa visão dicotômica, os homens eram vistos, usualmente, como inimigos e opressores, sendo excluídos das pautas de pesquisa e discussão (Figueroa-Perea, 2004).

Essa visão dicotômica foi criticada por grupos de mulheres negras, pobres e, ou, com orientaçôes afetivo-sexuais distintas da matriz heterossexual, que buscavam incluir nas reflexôes de gênero outras dimensões como a luta de classes, a discriminação racial e a diversidade afetivo-sexual. Assim, se a primeira onda enfatizou a luta pela igualdade entre homens e mulheres, a segunda buscava o reconhecimento e a valorização das diferenças entre homens e mulheres e, sobretudo, entre as próprias mulheres (Louro, 2001; Vazques, 2011).

É interessante notar que, no Brasil, como lembra Sarti (2004), o "movimento de mulheres" se encontrava em constante interação com outros movimentos sociais, como as organizações de bairro e os movimentos pelo fim da ditadura militar. Com o fim desse período e com o início do processo de democratização do País, o movimento feminista brasileiro ganhou forças na década de 1980 e continuou a mobilizar a sociedade em busca da igualdade de direitos entre homens e mulheres, tendo como suas principais lutas os direitos sexuais e reprodutivos, o fim da violência doméstica e, inclusive, a construção de ações e programas de saúde pública. A demanda por cidadania trazia a preocupação com a igualdade e, embora no plano teórico não houvesse ainda um rompimento com uma lógica binária, o movimento se colocava, na prática, como uma força de democratização da sociedade. 
No que diz respeito ao contexto internacional, surgia, ao final da década de 1970, a chamada terceira onda, caracterizada pelos estudos de gênero que, ao longo da década de 1980, incorporava também as preocupaçōes com os discursos sociais e sua força de constituição das subjetividades (Gonçalves, 1998; Louro, 2001). Desse modo, gênero passou a ser utilizado como uma categoria histórica e analítica (Scott, 1995).

Butler (2010) e Izquierdo (1998) apontam para o potencial que essa nova forma de conceber gênero traz para a análise das condições sociais e do processo de construção e manutenção das desigualdades sociais, rompendo com as polaridades e abrindo espaço para as pluralidades. Nesse sentido, é válido retomar a proposta de Scott (1995, p. 86): "O gênero é um elemento constitutivo de relaçôes sociais baseadas nas diferenças percebidas entre os sexos e [...] uma forma primária de dar significado às relações de poder".

Nessa nova transformação, percebeu-se a necessidade da inclusão dos homens nos debates e no movimento social, apontando a dimensão relacional de gênero e rompendo com o seu uso como categoria binária e descritiva (Butler, 2010). Foi nessa perspectiva que os estudos sobre homens tiveram início, rompendo com os estereótipos tradicionais e pensando as relações de gênero em uma sociedade mais equitativa (Medrado \& Lyra, 2008). Ao serem tomados como objeto de estudo, os homens e as masculinidades puderam ser compreendidos em sua historicidade, deixando, assim, de serem vistos de modo naturalizado.

Analisando a produção científica sobre as masculinidades, Figueroa-Perea (2004) destaca cinco abordagens recorrentes no campo do feminismo. $\mathrm{Na}$ primeira, os homens são representados como agressores e inimigos. A segunda, de maneira oposta, entende-os como vítimas do seu processo de socialização. Uma terceira concepção acentua essa posição de vítima, culpando as estruturas sociais pelas relações de dominação existentes. Na quarta concepção, já se encontram estudos sistemáticos sobre as desigualdades de gênero, porém ainda sem uma perspectiva crítica. Finalmente, a quinta concepção busca construir uma leitura histórica das relaçôes de gênero. Para Figueroa-Perea (2004), tratase de uma concepção ainda incipiente seja nas discussões políticas quanto na produção científica da área.

No campo da saúde coletiva, observa-se um número significativo de estudos sobre as mulheres, mas pouca produção sobre as vivências do público masculino. A incorporação do conceito de gênero nem sempre se dá em uma perspectiva crítica (Izquierdo, 1998; Medrado \& Lyra, 2008) e há dificuldade dos pesquisadores em romper com a perspectiva binária e dicotômica, pautadas em estereótipos e papéis sexuais (Araújo, Schraiber \& Cohen, 2011). Há, portanto, a necessidade 
de incorporar a perspectiva feminista crítica das relações de gênero nos estudos sobre as masculinidades e os processos sociais visando a uma compreensão contextualizada e articulada ao contexto sócio-histórico e político (Medrado \& Lyra, 2008).

Tanto quanto mobilizar a população masculina para os serviços de saúde, torna-se necessário sensibilizar e formar os trabalhadores da saúde para acolher e trabalhar as demandas do público masculino. Portanto se torna necessário incorporar essa questão nos cursos de formação na área da saúde, favorecendo a construção de práticas de saúde atentas ao contexto sociocultural e que considerem os usuários como agentes históricos e políticos, na perspectiva da integralidade. Esta foi a preocupação nesta pesquisa.

\section{Método}

A pesquisa foi desenvolvida com base em uma abordagem qualitativa (Minayo, 2007), por meio de um grupo focal que, segundo Gatti (2005), diz respeito a um conjunto de pessoas selecionadas e reunidas para discutir e comentar um tema específico, de interesse dos pesquisadores, com base em suas vivências pessoais, sendo uma metodologia adequada para se compreenderem processos de construção da realidade, representações, concepções, crenças, hábitos e valores.

Para a constituição do grupo, foram utilizados os seguintes critérios qualitativos de inclusão: ser graduando em Psicologia, possuir experiências de formação nos campos da saúde coletiva e dos direitos humanos, tais como em estágios e, ou, participação em projetos de pesquisa e extensão, e aceitar o convite de participação. Foram feitos convites via correio eletrônico para 15 estudantes que se encaixavam nos critérios de inclusão. Ao convidar esses estudantes para a pesquisa, nossa intenção não foi selecionar uma amostra para análise da formação em Psicologia, mas identificar os sentidos que alguns estudantes com experiência teórica e prática no campo da saúde estavam construindo sobre sua formação em Psicologia, com o objetivo de refletir e apontar situaçôes nas quais a perspectiva de gênero poderia se fazer presente na formação em saúde nos cursos de Psicologia.

Ao final, o grupo focal foi composto por sete estudantes de diferentes períodos do curso de Psicologia, matriculados em uma instituição de ensino superior privada em Belo Horizonte, Minas Gerais, sendo 6 mulheres e 1 homem, com idade entre 22 e 56 anos. O grupo foi conduzido seguindo os pressupostos de Gatti (2005), com base em um roteiro alicerçado: nas concepções dos estudantes sobre a relação dos homens com o processo de saúde/adoecimento/cuidado; nas representações do atendimento ao público masculino, na incorporação da questão de gênero na formação em Psicologia e nas opiniões sobre a PNAISH. 
A discussão foi gravada, transcrita e analisada por meio da análise de conteúdo, que é um conjunto de técnicas de análise de textos escritos ou transcrições que descreve, sistematiza e analisa seus conteúdos e significados (Bardin, 1976). Nesse sentido, realizaram-se leituras exaustivas do material transcrito e, em seguida, foram construídas categorias temáticas e unidades de significado que subsidiaram o processo de interpretação e construção dos resultados.

O projeto foi submetido e aprovado pelo Comitê de Ética em Pesquisas do Centro Universitário UNA. Os participantes foram esclarecidos acerca dos objetivos da pesquisa e assinaram o termo de consentimento livre e esclarecido (TCLE), em conformidade com a Resolução 196/1996 do Conselho Nacional de Saúde.

Buscando garantir o anonimato, os participantes tiveram seus nomes substituídos por siglas compostas pela letra "E" remetendo a "estudantes", seguida do número de identificação: E.1, E.2, E.3, consecutivamente.

A análise de conteúdo das falas dos estudantes apontou para as seguintes categorias: "Os modos de produção da existência e o delineamento das práticas de saúde" e "A temática de gênero na formação em Psicologia e a saúde do homem", que serão discutidas a seguir.

\section{Resultados e discussão}

Os participantes: seus contextos... suas histórias

Conforme aponta Sarti (2004), a análise sobre as relações de gênero exige a contextualização dos discursos, sendo necessária a escuta atenta do discurso do outro sobre o mundo social, possibilitando o diálogo e desvelando sentidos para a interpretação. Assim, procurou-se ouvir e analisar a fala dos participantes do grupo focal levando em consideração sua condição de sujeitos em um contexto social. Buscou-se contextualizar as suas diferenças quanto aos modos de se posicionar diante das relações entre gênero e saúde.

A primeira singularidade a ser constatada foi justamente a de pertencimento ao sexo feminino ou masculino e as implicações decorrentes desse pertencimento para se desenvolver uma dada reflexão: "Nós acabamos fazendo ações [em saúde], propondo ações de uma visão feminina. Porque nós somos mulheres, nós fomos criadas mulheres, crescemos mulheres [. . .]. Como eu vou olhar o homem a não ser sob uma ótica feminina?” (E.3).

Entretanto, apesar de situarem suas falas com base nos marcadores sexuais 
e de gênero, como destacado na fala acima, não foram percebidas diferenças significativas entre os discursos das participantes do sexo feminino em relação ao único participante do sexo masculino. Tal fenômeno pareceu ser mais bem compreendido ao se levar em conta, pelo menos, dois fatores importantes. $\mathrm{O}$ primeiro se referiu à homogeneidade da composição do grupo focal. Considerando-se os critérios de inclusão, já destacados, todos eram estudantes de Psicologia e já participaram de ações formativas no campo da saúde coletiva e direitos humanos. Outro fator importante que pode ter contribuído para certa homogeneidade das falas referiu-se ao fato de que os discursos e as concepções de gênero não se encontravam restritos a um único sexo. Conforme destaca Butler (2010), estes se encontram difundidos e impregnados em toda a sociedade, orientando modos de pensar, sentir e agir de homens e mulheres, de diferentes orientações sexuais, classes sociais, etnias, entre outros marcadores, em relação à temática.

Outra distinção foi relacionada à diferença geracional entre os participantes. Observou-se, em alguns momentos, um confronto entre estudantes de gerações distintas, mostrando as marcas ideológicas sobre seus modos de pensar sobre gênero e saúde. Abaixo, a sequência do diálogo do grupo mostra um exemplo:

[Em resposta a E.3, sexo feminino, 46 anos, que afirma que os homens desabafam no bar e as mulheres nos serviços de saúde, E.2, sexo feminino, 29 anos reage:] Ah eu discordo um pouco! Eu acho que a mulher também corre pra outros meios! [. . .] Eu, quando preciso desabafar, preciso conversar com alguém, eu vou pro barzinho conversar com os meus amigos. Quando eu tô doente, quando eu tenho uma queixa de saúde, é que eu vou ao centro de saúde (E.2).

[Em resposta à polêmica gerada pela fala anterior, E.3 rebate:] Só um esclarecimento antes: igual você falou, nossas idades são diferentes! A minha idade e a sua são bem diferentes! Assim: eu já sou avó, eu tenho dois filhos e tenho dois netos! (E.3).

Observa-se que os estudantes repetem os sentidos de gênero que foram demarcados por uma lógica binária e estereotipada, construindo oposições entre homens e mulheres como forma de explicar a desigualdade entre os sexos, no âmbito da saúde e da própria existência. Nesse sentido, os participantes associavam o cuidado com a saúde ao modo de ser das mulheres e o não cuidar da saúde ao modo de ser dos homens: "O homem ainda tem muita resistência na área da saúde [. . .] tem uma dificuldade mesmo em cuidar da sua própria saúde" (E.6). 
Entretanto, o grupo focal também abriu espaço para o confronto de ideias. Uma das participantes, remetendo-se a uma vivência familiar, foi além da visão dicotômica e conduziu o debate sobre a saúde masculina em uma perspectiva crítica e relacional:

É preciso se perguntar mesmo assim: mas, por quê? [. . . O O quê que faz que impeça que ele [o homem] se cuide? [. . . ] que que leva o homem a ter tanta dificuldade de entender que aquele corpo precisa de ajuda, que aquele corpo precisa de cuidado? [. . . ] o que que leva o homem a não se cuidar, mesmo sabendo que precisa daquele cuidado? (E.4, grifo nosso).

Esse questionamento permite ver que a experiência no cotidiano foi suficientemente forte para promover uma dissociação dos sentidos tradicionais e refletir sobre a relação dos homens com o processo de saúde/adoecimento e cuidado. A relação familiar e os sentimentos que surgiram na fala da participante mostram que os sujeitos são, muitas vezes, em seu cotidiano, sensibilizados e provocados para refletir sobre as questôes de gênero. É necessário então que haja espaços sociais e culturais onde essa reflexão possa encontrar ancoragem, tal como em um processo de formação acadêmica ou profissional.

\section{Os modos de produção da existência e o delineamento das práticas de saúde}

Segundo Spink (2003), as práticas de saúde são ações construídas, pactuadas e concretizadas no campo das relações sociais, históricas e políticas. Desse modo, pensar, sentir e agir em saúde não é mera aplicação de técnicas e procedimentos. Assim, é necessário superar a visão de que os homens são "naturalmente" resistentes aos cuidados em saúde. Pelo contrário, é preciso problematizar os elementos sociais e culturais que os levam a esse posicionamento, inclusive visando ao fortalecimento do acesso dos homens aos serviços. Essa percepção é importante para os profissionais e gestores de saúde, e poderia ser trabalhada no processo de formação na área da saúde, incluindo a Psicologia.

Urge compreender os elementos que contribuem para que o homem não cuide de sua saúde. A ênfase dada na fala da estudante E.4, citada anteriormente, denuncia que o impasse dessa questão não está restrito à informação e à cognição. Antes, aponta para uma lacuna entre o "saber" e o "fazer", em outras palavras, entre o estar ciente da necessidade de maiores cuidados e a efetividade das práticas, tal como vividas pelo sujeito. 
Observando os sentidos atribuídos pelos estudantes ao modo como os homens se colocam diante do processo de saúde/adoecimento/cuidado, percebese que esses sentidos se encontram fortemente associados ao contexto histórico, político e institucional, no qual homens e mulheres constroem e experienciam as práticas de cuidado. Nesse sentido, a relação dos participantes da pesquisa com o seu trabalho é um analisador significativo: "É a questão de não poder faltar de serviço, de muita mulher também, mas pra mulher ainda é mais maleável faltar de serviço pra cuidar da saúde do que pro homem" (E.3).

Esses dados apontam que a perspectiva binária do conceito de gênero também se encontra impregnada no discurso das organizaçôes contemporâneas. Nesse sentido, no interior das relações de trabalho e emprego, as desigualdades sociais, como aquelas pautadas nas diferenças sexuais e de gênero, encontram espaço profícuo para manifestação e (re)produção.

As falas dos entrevistados indicam a existência de uma "pactuação" social em que a mulher, comumente percebida como o "sexo frágil" e, portanto, carente de maiores cuidados de saúde, encontra legitimidade social para exercer o cuidado de si e dos outros. Já os homens, tendo em vista sua representação ligada ao trabalho produtivo e à invulnerabilidade, não encontrariam no campo organizacional a mesma autorização social para se ausentar de suas atividades laborais, da mesma forma como o fazem as mulheres.

Na prefeitura de [nome da cidade], a psicóloga que trabalha lá no RH queria fazer um projeto de saúde do homem [...], e ela começou a recolher alguns relatos e tal, e os homens falavam que não cuidavam da saúde porque eles eram os chefes da família e eles não poderiam se ausentar, e não poderiam saber da doença porque senão eles teriam que cuidar (E.2).

As unidades básicas de saúde (UBS) são, em sua maior parte, serviços diurnos, o que pode se constituir como barreira para acesso dos homens, por coincidir com a sua jornada de trabalho (Gomes, 2008; Figueiredo, 2005). Embora as mulheres também encontrem dificuldades para acessar os serviços diurnos, homens e mulheres encontram graus diferentes de tolerância para o absenteísmo no trabalho quando se trata de cuidar da saúde da família e, por extensão, da sua própria.

Segundo os estudantes, ao reconhecerem suas necessidades em saúde e se aproximarem das práticas de cuidado, os homens, em geral, vivem sentimentos de perda ou subtração da masculinidade: "Quando ele [o homem] consegue colocar isso: eu preciso de ir ao médico, seria como abrir mão da masculinidade 
dele, por causa desse posto de ser que pode tudo, esse ser que não cai por nada né" (E.7).

As discussões do grupo focal revelam a necessidade de incremento na formação em Psicologia para atuação profissional em saúde pautada numa perspectiva histórica das relações de gênero, menos descritiva e menos dicotômica. Uma pesquisa multicêntrica realizada em quatro Estados brasileiros mostrou que, entre os profissionais de saúde, ainda persistem os estereótipos que representam os homens como distantes, ausentes e resistentes ao cuidado com a saúde (Gomes et al., 2011). O ponto crítico é que essa invisibilidade dos homens é fruto de concepções estereotipadas sobre as relações de gênero, em uma lógica binária:

As identidades sociais de homens e mulheres elaboradas nas relaçôes sociais constroem não só modos de conceber o corpo, a saúde e a doença, mas, igualmente, produzem serviços de saúde baseados em modelos ideais de masculino e feminino que, ao mesmo tempo, permitem reconhecer necessidades específicas com relação à saúde das mulheres, normalizando-as na direção da reprodução biológica, dificultam visibilizar determinadas demandas relativas aos homens, por não serem identificadas com a lógica orientadora da assistência em saúde (Machin et al., 2011, p. 4).

É interessante notar que os participantes da pesquisa, durante o grupo focal, referiam-se à relação de homens e de mulheres com a saúde sempre de forma comparativa e opositiva. Por exemplo, apontavam que os homens, em sua maioria, encontram dificuldades para construção de vínculos com os serviços de saúde, enquanto as mulheres estão mais familiarizadas com eles e os utilizam mais. $\mathrm{Ou}$ seja, as falas sustentavam sentidos binários pautados na visão da desigualdade de gênero. Portanto reproduziam os estereótipos sobre gênero e saúde: "Mulher não espera estar aguda pra ela estar ali no médico, pra ela estar buscando entender o que que tá acontecendo com ela" (E.5) e "A realidade do centro de saúde ainda é $80 \%$ do público feminino. Impressionante! Qualquer horário que você vai, cheio ou vazio, é fato que as mulheres estão mais!" (E.1).

Conforme destacam Machin et al. (2011), os sentidos que os profissionais atribuem à relação entre gênero e saúde acabam por materializar-se nas práticas assistenciais disponibilizadas, com a reprodução das desigualdades sociais de gênero. De forma correlacionada, ao tratar da relação entre gênero e saúde, os participantes deste estudo expressaram ideias essencialistas e naturalizantes: "A mulher por si ela já é mais cuidadosa! A mulher já tem aquele instinto maternal, aquela proteção de natureza. Então eu acho que realmente a mulher busca mais isso [cuidar da saúde]" (E.2, grifos nossos). 
Essas concepções, contudo, encontram-se ancoradas em experiências que organizam os modos de produção da existência, especialmente no trabalho e na família, conforme apresentado pelos participantes da pesquisa. Em decorrência, pois, apontamos para a importância da formação universitária não se restringir à dimensão cognitiva de acúmulo de informaçôes, mas também abrir espaço para a reflexão sobre essas experiências e o desenvolvimento de ações de pesquisa, ensino e extensão que possibilitem a reflexão crítica sobre as diversas formas de organização social.

Por outro lado, os estudantes também apontaram para transformações nas relaçōes de gênero, sobretudo no que se refere à conquista de alguns direitos pelas mulheres, como o voto e a inserção no mercado de trabalho. O reconhecimento do caráter histórico dos sentidos de gênero é o que possibilita projetos de atuação. Isso leva a refletir sobre a formação universitária como espaço crítico-reflexivo, incorporando as discussóes de gênero no campo da Psicologia e da saúde em um âmbito maior.

\section{A temática de gênero na formação em Psicologia e a saúde do homem}

Bernardes (2006) ressalta que a construção dos processos educativos não acontece alheia à história e aos embates políticos, econômicos e sociais. As instituiçóes formadoras se configuram como produtos e produtoras de cultura e, além de influenciar a construção da identidade profissional, são responsáveis pela produção e delineamento de subjetividades.

Como destaca Bernardes (2006), os currículos trazem as marcas históricas das disputas de poder, respondendo às demandas da cultura na qual se organiza, priorizando saberes e práticas de acordo com as disputas ideológicas dentro do campo de saber. O autor também chama a atenção para a necessidade de se incorporar, na formação em Psicologia, os princípios do SUS, sobretudo, a integralidade. Argumenta que o movimento feminista tem contribuído para essa integração, sobretudo nas discussões sobre políticas públicas e gênero.

Narvaz (2009) destaca que a temática de gênero está pouco incorporada na formação profissional em Psicologia. Porém cabe ressaltar que a temática "gênero e saúde" pode ser trabalhada de maneira transversal em disciplinas diversas, como Psicologia social, Antropologia e Sociologia. Para os estudantes desta pesquisa, o conceito de gênero, quando utilizado em sua formação, foi relacionado, na maioria das vezes, às questões das mulheres, sobretudo em condiçôes de violência sexual e doméstica, abrindo pouco espaço para reflexão sobre o homem: "Se a gente viu projetos foi tudo com a violência feminina, Lei Maria da Penha. E a gente, assim, como eu falei, foi a primeira vez que eu ouvi alguém falar assim: alguma coisa pra homem" (E.4). 
Os estudantes destacam que a questão da saúde do homem fica reduzida à especificidade do câncer de próstata, sobretudo ao exame de toque retal. Além disso, os homens ainda ocupam um lugar marginalizado nas discussões de gênero:

Eu sempre, desde o primeiro período da graduaçãa, eu consigo entender por que que a mulher apanha, por que que a mulher de repente perdoa [. . . . Mas eu não consigo entender o homem, porque eu não tive nada que me dissesse, alguém que me dissesse assim: ó, o homem que bate na mulher é assim, o dele também são em fases. Ele bate depois se arrepende. Eu não tive. [. . .] Pra atender homem não. Mas pra atender uma mulher agredida, eu tenho uma base sim. A partir disso, eu talvez consiga atender um homem (E.4).

A saúde masculina ainda é um tema pouco incorporado no âmbito da produção científica (Araújo et al., 2011) e a própria PNAISH ainda está em implantação no que se refere à gestão e delineamento de ações assistenciais do SUS. Essa invisibilidade foi evidenciada na fala de uma das participantes da pesquisa: "Você pode ver que, até nos próprios programas de atenção básica, você tem a atenção ao idoso, atenção à gestante, atenção à mulher, atenção bucal, a atenção ao adolescente, mas você não vê atenção ao homem" (E.3).

Por outro lado, no grupo focal, constatou-se que a perspectiva relacional de gênero começa a ser discutida, ainda que de forma tímida, no processo de formação. Os estudantes chamam a atenção para a impossibilidade de se problematizar as questôes relacionadas às mulheres sem levar em conta sua relação com os homens, em conformidade com uma perspectiva relacional, histórica e contextualizada (Sarti, 2004; Scott, 1995).

Então, acho que a formação, mesmo que tenha um pouco mais de enfoque na mulher, acaba sendo no homem também. O oposto acaba indo junto [...] A gente teve um enfoque, eu senti isso, até então, em relação ao gênero feminino. Mas é porque, quando você fala do gênero feminino, você acaba falando do gênero masculino, provavelmente tem coautores, tem uma relação. Então indiretamente tem uma formação sim (E.2).

Observou-se que a PNAISH é desconhecida pelos estudantes, sendo que apenas uma entrevistada tinha ouvido falar sobre ela em sua formação. Por outro lado, os participantes se recordaram de algumas ações midiáticas do Ministério da Saúde, como propagandas e outras peças publicitárias no rádio e na televisão, que ainda se encontram voltadas para as mulheres: "Teve até uma campanha nacional né: 'Leve seu marido ao médico!' A campanha era assim. Não era um 
chamado para os homens, era um chamado para as mulheres" (E.2).

Segundo Barker e Greene (2011), a ênfase na mobilização das mulheres para alcançar os homens reflete um discurso, constituinte das próprias políticas públicas, que parece desacreditar a população masculina, seus modos de ser sujeito e de se transformar. Os estudantes também mostraram dificuldade de considerar os homens como sujeitos das políticas públicas: "Eu acho, assim, que se pensarmos bem, as políticas públicas foram formadas em cima dos grupos vulneráveis, e o homem nunca foi visto como um grupo vulnerável. Talvez por isso ele tenha ficado, não tenha nada focado diretamente nele" (E.1).

A fala acima reflete uma lógica de desigualdade social na qual o homem é representado como forte e pouco vulnerável, não necessitando de ações de saúde. Em sua maioria, as políticas públicas de saúde estão voltadas para os grupos vulnerabilizados, tais como mulheres, negros e pobres. E é conflitante perceber os homens nessa condição.

Mas como o psicólogo pode se posicionar diante das desigualdades de gênero? Quais as possibilidades de atuação em programas, políticas e ações de saúde pautadas pelo princípio da integralidade? Esses são questionamentos que surgem da incorporação de gênero como uma categoria analítica dos processos de pensar, sentir e agir em saúde.

Nesse sentido, há necessidade de atuação sobre o processo de socialização e construção de identidades, questionando tabus e discursos já instituídos, abrindo espaço para mudanças de pensamentos e de posturas diante da alteridade. Como aponta Izquierdo (1998), não basta apenas melhorar a vida de homens ou mulheres, mas devem ser construídos espaços de luta em um sistema pautado nas desigualdades sociais. Nesse sentido, os estudantes também buscaram apontar novas formas de ação: "Não só adaptar a saúde pra receber o homem e também colocar a urologia, por uma equipe ali. Também quebrar esses tabus até culturais: homem não chora, quebrar isso aos poucos. Educação também é importante" (E.7).

Outro campo de atuação apontado pelos estudantes se refere à possibilidade de o psicólogo não ficar restrito ao atendimento de necessidades manifestas, mas abrir espaços para propor ações e construir demandas. Assim, é preciso que o profissional de saúde problematize a ausência masculina: "Eu acho que uma das formas que o psicólogo pode ajudar nisso é no atendimento familiar né, fazendo esse chamado: ah, o seu marido não veio!" (E.2).

Para tanto, é preciso que o trabalho do psicólogo alcance os diversos contextos sociais, abrindo-se para a construção de ações coletivas e interdisciplinares, 
favorecendo a interlocução entre diferentes atores e saberes. Nessa direção, uma das entrevistadas ressalta a necessidade de "ir aonde os sujeitos estão", ultrapassando o modelo biomédico.

\begin{abstract}
A Psicologia tem vários espaços, a gente tá em vários deles, e essa questão de promover saúde e bem-estar é um pouco disso assim: conseguir olhar pra esse sujeito que tá ali e fazer pequenas ações em cada espaço que vão incluindo, que vão colocando isso. É o centro de saúde que tem um projeto, é um projeto pra escutar esses agressores e entender por quê, [...] Projeto Caminhar, o futebol do final de semana, por que não estar ali? Por que não aproveitar essas coisas? (E.5).
\end{abstract}

Por último, mas não menos importante, os entrevistados destacam que a construção de ações pautadas em uma perspectiva de gênero somente poderá se efetivar a partir da compreensão dos diferentes modos de ser dos diferentes sujeitos, sejam eles homens ou mulheres:

Procurar entender como o homem se relaciona com a saúde pra também saber o que fazer! Que não adianta a gente querer fazer a ação. Acho que é esse movimento de saber como se pensa é o primeiro caminho assim para promover a saúde do homem e fazer um pouquinho da Política Nacional [PNAISH] (E.5).

Conforme destaca Ferreira Neto (2011), a entrada da Psicologia no campo das políticas públicas de saúde exigiu transformações na atuação, na produção do conhecimento científico e na formação universitária. Esse desafio se torna mais complexo diante da necessidade de incorporar os princípios da saúde, englobando gênero como categoria analítica.

\title{
Considerações finais
}

Neste estudo, buscamos conhecer os sentidos que estudantes de Psicologia atribuem à relação entre gênero e saúde, em especial, à saúde do homem. Observou-se que, tratando-se de sujeitos históricos que existem e se constituem em um contexto marcado pelas desigualdades de gênero, os estudantes têm o discurso marcado por concepçôes que ainda associam as mulheres ao cuidado e os homens ao risco e não cuidado com a saúde.

A análise do grupo focal revela que a experiência de vida dos entrevistados e suas vivências acadêmicas encontram-se fortemente articuladas, contribuindo 
para a manifestação e (re)produção de estereótipos de gênero nos modos como esses sujeitos significam a relação dos homens e mulheres com as práticas de cuidado.

Nota-se que, apesar das recentes transformações curriculares, a problematização das questóes de gênero, especialmente no que se refere ao tema das masculinidades, ainda se refere a uma lacuna na formação em Psicologia. Quando presentes, as discussões de gênero parecem priorizar as questôes relacionadas às mulheres, numa perspectiva binária, pouco crítica e historicizada. Os sentidos binários e dicotômicos prevaleceram nas falas dos estudantes, mostrando a importância de se investir em uma proposta formação que ultrapasse a transmissão de informaçōes e que prepare os futuros psicólogos para a atuação no contexto das políticas públicas de saúde.

Entretanto é preciso destacar que, dado o seu caráter relacional, torna-se imprescindível que a inclusão da temática de gênero na formação em Psicologia se concretize de forma transversal, de modo que as discussões sobre o tema não estejam restritas a um grupo de disciplinas específicas. Além disso, são necessários esforços para a construção de espaços críticos e reflexivos na formação em Psicologia; não necessariamente restritos às salas de aulas e, ou, presos às "grades" curriculares, que promovam discussões acerca da temática de gênero que incluam homens e mulheres, de diferentes raças e etnias, distintas orientações sexuais, classes sociais, em uma perspectiva crítica e relacional.

O SUS é um projeto social sonhado, inventado, forjado e conduzido, cotidianamente e com suas contradiçôes, por sujeitos históricos, políticos e sociais. No entanto, é urgente refletir sobre a "genderificação" dos serviços de saúde, reproduzindo a lógica das desigualdades e iniquidades sociais. Pensado sob essa perspectiva, o SUS se torna tão contraditório e dialético como são contraditórios e dialéticos aqueles que lhe deram e lhe dão vida nas formas cotidianas da política.

A inclusão dos psicólogos nesse campo, marcado pela complexidade dos sujeitos que o constituem, exige uma análise crítica e, mais do que isso, a transformação constante dos projetos políticos-pedagógicos dos cursos de Psicologia. Tendo em vista o seu caráter estruturante dos modos de pensar, sentir e agir dos sujeitos, acreditamos que as teorias de gênero, se consideradas como conteúdo transversal à formação, poderão contribuir para práticas profissionais contextualizadas e para a efetividade dos princípios da equidade, universalidade e integralidade, estruturantes do SUS.

A incorporação das questôes de gênero na formação em Psicologia e, como discutido neste estudo, da associação entre gênero e saúde certamente nos 
exigirá um esforço de mudança que, por sua vez, poderá impulsionar novos conhecimentos e novas pesquisas. Defrontamo-nos, assim, com um importante desafio: transformar os processos formativos, que englobam não apenas o ensino, mas também as práticas de pesquisa e extensão.

Enfim, é preciso perguntar constantemente sobre a nossa atuação como psicólogos, visando a (re)construir referências para a nossa atuação como produtores de conhecimento e para o reconhecimento de nossas práticas profissionais. Perguntar, como nos ensinou Paulo Freire:

Há perguntas a serem feitas insistentemente por todos nós e que nos fazem ver a impossibilidade de estudar por estudar. De estudar descomprometidamente como se misteriosamente, de repente, nada tivéssemos que ver com o mundo, um lá fora e distante mundo, alheado de nós e nós dele. Em favor de que estudo? Em favor de quem? Contra que estudo? Contra quem estudo? (Freire, 1998, p. 86)

Finalizamos nossas considerações, pois, ressaltando a necessidade de promovermos uma formação que inclua a reflexão sobre os modos de produção de existência dos próprios estudantes e o compromisso com a construção de novas possibilidades e alternativas para enfrentamento das questôes impostas pela realidade sócio-histórica brasileira. 


\section{Referências}

Araújo, M. F., Schraiber, L. B. \& Cohen, D. D. (2011). Penetração da perspectiva de gênero e análise crítica do desenvolvimento do conceito na produção científica da Saúde Coletiva. Interface: Comunicação, Saúde, Educação, 15, 805-818.

Bardin, L. (1976). Análise de conteúdo. São Paulo: Martins Fontes.

Barker, G. \& Greene, M. E. (2011). ¿Qué tiene que ver los hombres con esto?: reflexiones sobre la inclusión de los hombres y las masculinidades en las políticas públicas para promover la equidad de género. In F. Aguayo \& $\mathrm{M}$. Sadler (Orgs.), Masculinidades y políticas públicas: involucrando hombres en la equidad de género. (pp. 23-48). Santiago: Universidad de Chile.

Bernardes, J. (2006). Formação generalista em Psicologia e Sistema Único de Saúde. In Anais, 1 Fórum Nacional de Psicologia e Saúde Pública: contribuições técnicas e politicas para avançar o SUS. (pp. 17-40). Brasília: Conselho Federal de Psicologia.

Brasil. Ministério da Saúde. (2009). Política Nacional de Atenção Integral à Saúde do Homem: princípios e diretrizes. Brasília: Ministério da Saúde.

Butler, J. (2010). Problemas de gênero: feminismo e subversão da identidade. Rio de Janeiro: Civilização Brasileira.

Ferreira Neto, J. L. (2010). Uma genealogia da formação do psicólogo brasileiro. Memorandum, 18, 130-142.

Ferreira Neto, J. L. (2011). Psicologia, políticas públicas e o SUS. Belo Horizonte: Escuta, Fapemig.

Figueiredo, W. S. (2005). Assistência à saúde dos homens: um desafio para os serviços de atenção primária. Ciência \& Saúde Coletiva, 10, 105-109.

Figueroa-Perea, J. G. (2004). La representación social de los varones en estudios sobre masculinidad y reproducción: un muestrario de reflexiones. In B. Medrado, M. Franch, J. Lyra, M. Brito (Orgs.), Homens: tempos, práticas e vozes. (pp. 22-38). Recife: Instituto Papai/Fages/Nepo/Pegapacapá.

Freire, P. (1998). Pedagogia da autonomia: saberes necessários à prática educativa. (9a ed.). Rio de Janeiro: Paz e Terra. 
Gatti, B. A. (2005). Grupo focal na pesquisa em Ciências Sociais e Humanas. Brasília: Liber.

Gomes, R. (2008). Sexualidade masculina, gênero e saúde. Rio de Janeiro: FIOCRUZ. (Coleção Criança, Mulher e Saúde).

Gomes, R., Moreira, M. C. N., Nascimento, E. F., Rebello, L. E. F. S., Couto, M. T. \& Schraiber, L. B. (2011). Os homens não vêm! Ausência e/ou invisibilidade masculina na atenção primária. Ciência \& Saúde Coletiva, 16, 983-992.

Gonçalves, E. (1998). Pensando o gênero como categoria de análise. In M. J. P. Rocha (Org.), Estudos de gênero (pp. 41-60). Goiânia: Universidade Católica de Goiás, Programa Interdisciplinar da Mulher.

Guareschi, N. M. F., Dhein, G., Reis, C., Machry, D. S. \& Bennemann, T. (2010). A Psicologia e a formação do profissional da saúde para o SUS: um estudo a partir dos currículos de cursos de psicologia do Rio Grande do Sul. In N. M. F. Guareschi, G. Dhein, C. Reis, D. S. Machry \& T. Bennemann (Orgs.), Psicologia, formação, políticas e produção em saúde. (pp. 29-53). Porto Alegre: Editora PUC-RS.

Izquierdo, M. J. (1998). Sexo, género e individuo. El sistema sexo/genero como marco de análisis. In Izquierdo, M. J. El malestar en la desigualdad. (pp. 7-56). Madri: Catedra.

Louro, G. L. (2001). A emergência do "gênero". In G. L. Louro, Gênero, sexualidade e educação: uma perspectiva pós-estruturalista. (pp. 14-36). Petrópolis: Vozes.

Machin, R., Couto, M.T., Silva, G. S. N., Schraiber, L. B., Gomes, R., Figueiredo, W. S., ... Pinheiro, T. F. (2011). Concepções de gênero, masculinidade e cuidados em saúde: um estudo com profissionais de saúde da atenção primária. Interface: comunicação, saúde, educação, 14, 257-270.

Mattos, R. A. (2004). A integralidade na prática (ou sobre a prática da integralidade). Cadernos de Saúde Pública, 20, 1411-1416.

Medrado, B. \& Lyra, J. (2008). Por uma matriz feminista de gênero para os estudos sobre homens e masculinidades. Estudos Feministas, 16, 809-840.

Minayo, M. C. S. (2007). O desafio do conhecimento: pesquisa qualitativa em saúde. São Paulo: Hucitec. 
Narvaz, M. G. (2009). A (in)visibilidade do gênero na Psicologia acadêmica: onde os discursos fazem(se) politica. (Tese de Doutorado). Universidade Federal do Rio Grande do Sul, Instituto de Psicologia, Porto Alegre.

Romagnoli, R. C. (2011). Reflexôes acerca da formação dos psicólogos e sua relação coma saúde pública. In L. Kind, C. B. Batista \& L. Gonçalves (Orgs.), Universidade e serviços de saúde: interfaces, desafios e possibilidades na formação profissional em saúde. (pp. 111-128). Belo Horizonte: Editora PUC Minas.

Sarti, C. A. (2004). O feminismo brasileiro desde os anos de 1970: revisitando uma trajetória. Estudos Feministas, 12, 35-50.

Scott, J. (1995). Gênero: uma categoria útil de análise histórica. Educação \& Realidade, 20, 71-99.

Spink, M. J. (2003). Psicologia Social e saúde: práticas, saberes e sentidos. Petrópolis: Vozes.

Vazques, M. G. (2011). Algunas reflexiones acerca del género desde la Historia. In J. C. C. Ríos (Org.), El género a debate: reflexiones teóricas y metodológicas multidisciplinarias. (pp. 09-29). Guadalajara: Universidad de Guadalajara. 